\title{
Perspective validation of the eurofever classification criteria for monogenic periodic fevers
}

\author{
Silvia Federici ${ }^{1 *}$, P Dolezalova ${ }^{2}$, L Cantarini ${ }^{3}$, E Papadopoulou-Alataki ${ }^{4}$, M Alessio ${ }^{5}$, T Herlin $^{6}$, I Gueli ${ }^{1}$, C Modesto $^{7}$, \\ G Fabio $^{8}$, MC Maggio $^{9}$, MJ Rua Elorduy ${ }^{10}, \mathrm{~F}$ Garibotto ${ }^{1}$, A Insalaco ${ }^{11}$, A Kozlova $^{12}$, J Anton ${ }^{13}$, R Brik $^{14}$, J Frenkel ${ }^{15}$, \\ E Hoppenreijs ${ }^{16}$, MP Sormani ${ }^{1}$, Alberto Martini ${ }^{1}$, Marco Gattorno ${ }^{1}$
}

From 21st European Pediatric Rheumatology (PReS) Congress

Belgrade, Serbia. 17-21 September 2014

\section{Introduction}

We recently proposed a set of provisional, evidence-based, clinical criteria for the classification of children and adults patients affected by monogenic periodic fevers. These criteria, built and validated in a cohort of 1215 patients with periodic fever enrolled in the Eurofever Registry from November 2009 to February 2013, displayed a high sensitivity and specificity.

\section{Objectives}

To prospectively validate the provisional Eurofever clinical classification criteria in an independent set of patients with periodic fevers enrolled in the registry after March 2013

\section{Methods}

The provisional Eurofever classification criteria (best accuracy cut-off) were applied to patients with periodic fevers enrolled in the registry after March 2013. The following disease were analyzed: FMF, MKD, TRAPS,
CAPS, PFAPA and undefined periodic fevers. Patients were divided in three subgroups: i) group A: inherited periodic fevers with genetic confirmation, ii) group B: inherited periodic fevers with non-confirmatory genetic test, iii) group C: negative controls. Statistical analysis compared the sensitivity and specificity of best accuracy cut-off in patients belonging to group $\mathrm{A}$ and $\mathrm{C}$.

\section{Results}

A total of 245 patients were evaluated. Among them 80 were classified in group A (35 FMF, 28 MKD, 9 TRAPS, 8 CAPS), 94 in group B (56 FMF, 6 MKD, 9 TRAPS, 23 CAPS) and 71 in group C (59 PFAPA and 12 undefined periodic fever). The classification criteria tested on patients belonging to Group A and C displayed an overall good sensitivity and specificity (respectively $85 \%$ and $92 \%$ for FMF, $92 \%$ and $89 \%$ for MKD, $100 \%$ and $96 \%$ for CAPS and $100 \%$ and $93 \%$ for TRAPS). (see table 1). The performance of the classification criteria in patients with nonconfirmatory genetic test are reported in Table 1 below.

Table 1

\begin{tabular}{|c|c|c|c|c|c|c|c|c|}
\hline & \multicolumn{4}{|c|}{$\begin{array}{c}\text { Sensitivity } \\
\text { (Best Accuracy cut-off) }\end{array}$} & \multicolumn{4}{|c|}{$\begin{array}{c}\text { Specificity } \\
\text { (Best Accuracy cut-off) }\end{array}$} \\
\hline & FMF & MKD & CAPS & TRAPS & FMF & MKD & CAPS & TRAPS \\
\hline Genetically confirmed (Group A) & $85 \%$ & $92 \%$ & $100 \%$ & $100 \%$ & $92 \%$ & $89 \%$ & $96 \%$ & $93 \%$ \\
\hline Not genetically confirmed (Group B) & $58 \%$ & $67 \%$ & $45 \%$ & $25 \%$ & $94 \%$ & $79 \%$ & $100 \%$ & $82 \%$ \\
\hline
\end{tabular}

${ }^{1}$ UO Pediatria 2, IRCCS Gaslini, Genova, Italy

Full list of author information is available at the end of the article 


\section{Conclusion}

Perspective validation of Eurofever classification criteria showed their good accuracy in patients with confirmatory genetic test. Despite a lower sensitivity, the criteria displayed an high specificity in the classification of patients with non-confirmatory molecular test. In order to evaluate the actual accuracy of the classification criteria in this latter subgroup, an expert validation is currently ongoing.

\section{Disclosure of interest}

None declared.

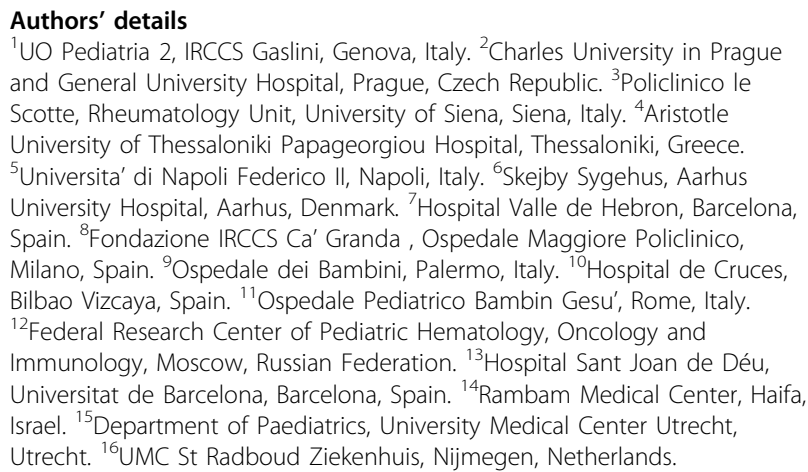

Published: 17 September 2014

doi:10.1186/1546-0096-12-S1-P82

Cite this article as: Federici et al:: Perspective validation of the eurofever classification criteria for monogenic periodic fevers. Pediatric

Rheumatology 2014 12(Suppl 1):P82.

\section{Submit your next manuscript to BioMed Central} and take full advantage of:

- Convenient online submission

- Thorough peer review

- No space constraints or color figure charges

- Immediate publication on acceptance

- Inclusion in PubMed, CAS, Scopus and Google Scholar

- Research which is freely available for redistribution

Submit your manuscript at www.biomedcentral.com/submit 